\title{
Injury-Induced Upregulation of bFGF and CNTF mRNAS in the Rat Retina
}

\author{
Rong Wen, ${ }^{1,2}$ Ying Song, ${ }^{1,2}$ Tong Cheng, ${ }^{1,2}$ Michael T. Matthes, ${ }^{2,3}$ Douglas Yasumura, ${ }^{2,3}$ Matthew M. LaVail, ${ }^{2,3}$ \\ and Roy H. Steinberg ${ }^{1,2}$ \\ Departments of ${ }^{1}$ Physiology, ${ }^{2}$ Ophthalmology, and ${ }^{3}$ Anatomy, University of California, San Francisco, San Francisco, \\ California 94143
}

Focal mechanical injury to the retina has been shown to slow or prevent photoreceptor degeneration near the lesion site in two animal models of retinal degeneration, inherited retinal dystrophy in the Royal College of Surgeons (RCS) and light damage in albino rats. Thus, when injured, the rat retina activates a self-protective mechanism to minimize damage. To identify injury responsive factors and cells, we examined the mRNAs for the following factors and some of their receptors: basic and acidic fibroblast growth factors (bFGF, aFGF) and FGF receptor-1 (FGFR1); ciliary neurotrophic factor (CNTF) and CNTF receptor $\alpha$ (CNTFR $\alpha$ ); brain-derived neurotrophic factor (BDNF) and its receptor trkB; and insulin-like growth factor-1 (IGF-1) and IGFR-1 receptor (IGF-1R). After a single mechanical lesion to the subretinal space and retina, there was a substantial increase in bFGF and CNTF expression that persisted for the entire $10 \mathrm{~d}$ period of study. The increase in bFGF mRNA after injury was prompt and great in amplitude, while the elevation of CNTF mRNA was relatively slower. In addition, there was a transient increase in FGFR1 mRNA. In situ hybridizations showed that the elevation of bFGF and CNTF was localized to the vicinity of the lesion. The expression of GFAP (glial fibrillary acidic protein) mRNA also increased in response to injury. These findings strongly suggest that increases in endogenous bFGF and/ or CNTF play key roles in injury-induced photoreceptor rescue.

[Key words:neurotrophic factors, growth factors, bFGF, CNTF, FGFR1, GFAP, CNS injury, retinal injury, photoreceptors, Müller cell, rat]

It is known that focal injury to rat retina protects photoreceptors from degeneration (Steinberg, 1994). In the Royal College of Surgeons rat (RCS) with an inherited photoreceptor degeneration, mechanical injury produced by an injection of saline into the subretinal space, or into the vitreous, or even a needle in-

\footnotetext{
Received May 9. I995; revised July 5, 1995; accepted July 10, 1995.

We thank Drs. Yiwen Li, Nancy Y. Ip, and George Yancopoulos for their help and support. This work was supported by a Grant-in-Aid from the Leona and Harry Helmsley Fund of Fight for Sight, lnc., New Yulk City (R.W.); an Academic Senate grant from UCSF (R.W.); a REAC grant from UCSF, School of Medicine (R.W.); NIH Grants EYO1919 (M.M.L.), EY06842 (M.M.L.), and EYO1429 (R.H.S.); and funds from the Retinitis Pigmentosa Foundation and That Man May See Inc.

Correspondence should be addressed to Dr. Rong Wen, Department of Physiology, Box 0444, University of California, San Francisco, San Francisco, CA 94143-0444.

Copyright 1995 Society for Neuroscience $\quad 0270-6474 / 95 / 157377-09 \$ 05.00 / 0$
}

sertion without injection, protects photoreceptors near the wound (Faktorovich et al., 1990; Silverman and Hughes, 1990; Blair et al., 1991; Li et al., 1991). In constant light-induced photoreceptor degeneration, a similar injury-dependent protection is observed (Faktorovich et al., 1992). These findings imply that the retina has a self-protective mechanism whose activation protects photoreceptors from damage and death. A similar self-protective mechanism appears to exist for retinal ganglion cells (MansourRobey et al., 1994).

Several lines of evidence suggest that endogenous factors that promote photoreceptor survival may be involved in this selfprotective mechanism. First, the finding that injury-induced photoreceptor rescue extends beyond the immediate vicinity of the lesion (Faktorovich et al., 1990, 1992; Silverman and Hughes, 1990 ) suggests that soluble factors are involved. Second, a number of factors that exhibit neurotrophic activity are expressed in the retina, especially aFGF (Hicks et al., 1991), bFGF (Hicks et al., 1991), CNTF (Kirsch et al., 1993; Wen et al., 1994), and IGF-1 (Danias and Stylianopoulou, 1990). Also, exogenous factors have been shown to rescue photoreceptors in RCS and lightdamaged rats when injected into the eye (Faktorovich et al., 1990, 1992; LaVail et al., 1992). Furthermore, focal injury to the brain upregulates a number of endogenous factors (Finklestein et al., 1988; Nieto-Sampedro et al., 1988; Frautschy et al., 1991; Garcia-Estroda et al., 1992; Logan et al., 1992; Ip et al., 1993), indicating that they are involved in injury responses of neuronal tissue.

The purpose of the present work was an attempt to identify the injury-responsive factors and cells in the neural retina that may be responsible for injury-induced photoreceptor protection. We examined the mRNA expression of five factors and some of their receptors: basic and acidic fibroblast growth factors (bFGF aFGF) and FGF receptor-1 (FGFR 1); ciliary neurotrophic factor (CNTF) and CNTF receptor $\alpha$ (CNTFR $\alpha$ ); brain-derived neurotrophic factor (BDNF) and its receptor $t r k \mathrm{~B}$; and insulin-like growth factor-1 (IGF-1) and IGFR-1 receptor (IGFR-1R). The selection of factors was based on their presence in retina and their ability to rescue photoreceptors when injected into the rat eye (Faktorovich et al., 1990, 1992; LaVail et al., 1992; Robbins et al., 1993). A substantial increase in bFGF and CNTF expression was observed following injury, along with a transient increase in FGFR I mRNA. Considering that exogenous bFGF and CNTF rescue photoreceptors in the rat (Faktorovich et al., 1990, 1992; LaVail et al., 1992), our findings strongly suggest that increases in endogenous bFGF and/or CNTF play key roles in injury-induced photoreceptor rescue. 


\section{Materials and Methods}

Animals and surgery. Male Sprague-Dawley rats, 2-3 months of age, were used in all experiments. Animals were kept in a $12 \mathrm{~L}: 12 \mathrm{D}$ cycle at an in-cage illuminance of $<25$ foot-candles for $7 \mathrm{~d}$ prior to experiments. Animals were anesthetized with a ketamine-xylazine mixture (ketamine, $40 \mathrm{mg} / \mathrm{kg}$, xylazinc, $6 \mathrm{mg} / \mathrm{kg}$, i.m.). Mechanical injury was made by a $1 \mathrm{~mm}$ incision through the sclera, choroid, and retinal pigment epithelium (RPE), down through the subretinal space and into the outer retina, using a sharp blade on the superior hemisphere of an eye.

Histology. Eyes of selected animals were examined histologically to define the extent of damage made by the mechanical injury and to determine whether the extent of rescue from constant light differed from that produced by a needle insertion (Faktorovich et al., 1992). Injury was made to one eye of an animal, and the other eye, which was uninjured, served as control for light damage. Two days following injury, animals were placed into constant fluorescent light at an illuminance level of 115-200 ft-c for a period of $7 \mathrm{~d}$, as described elsewhere (Faktorovich et al., 1992). Animals not exposed to constant light served as normal controls. The rats were then killed by overdose of $\mathrm{CO}_{2}$ followed immediately by vascular perfusion of mixed aldehydes (LaVail and Battelle, 1975). The eyes were embedded in an Epon/Araldite mixture for sectioning at $1 \mu \mathrm{m}$ thickness to provide sections of the entire retina along the vertical meridian of the eye, as previously described (LaVail and Battelle, 1975).

RNA extraction and Northern blot analysis. Animals were killed by $\mathrm{CO}_{2}$ overdose and retinas were taken $0.5,1,2,4,7$, and $10 \mathrm{~d}$ following injury. Retinas from animals without injury served as controls. Whole retinas were dissected, snap frozen in liquid nitrogen, and stored at $-80^{\circ} \mathrm{C}$. Pooled retinas were homogenized in $5.5 \mathrm{M}$ guanidinium thiocyanate solution $(5.5 \mathrm{~m}$ guanidinium thiocyanate, $25 \mathrm{~mm}$ sodium citrate, $0.5 \%$ sodium lauryl sarcosine, $\mathrm{pH} 7.0$ ), and total RNA was isolated using a CsTFA (cesium trifluoroacetate, Pharmacia, Piscataway, NJ) gradient method (Farrell, 1993). Total RNA ( $20 \mu \mathrm{g}$ of each sample) was electrophoresed on $1 \%$ agarose formaldehyde gels and downward wick transferred in $20 \times \mathrm{SSC}(1 \times \mathrm{SSC}=0.15 \mathrm{M} \mathrm{NaCl}, 0.15 \mathrm{M}$ sodium citrate, $\mathrm{pH} 7.0$ ) to a nylon membrane (Hybond-N, Amersham, Arlington Heights, IL). Blots were UV irradiated to immobilize RNA and then prehybridized for $4 \mathrm{hr}$ in a hybridization solution containing: $50 \%$ formamide, $5 \times$ Denhardt's solution, $5 \times \operatorname{SSPE}(1 \times \mathrm{SSPE}=0.15 \mathrm{M} \mathrm{NaCl}$, $10 \mathrm{~mm} \mathrm{NaH}, \mathrm{PO}_{4}, 1 \mathrm{~mm}$ EDTA, pH 7.4), $200 \mu \mathrm{g} / \mathrm{ml}$ denatured salmon sperm DNA, and $5 \%$ SDS at $50^{\circ} \mathrm{C}$. Random primed "P-labeled cDNA probes [bFGF, 477 base pair (bp) rat cDNA, gift of Dr. A. D. Baird (Shimasaki et al., 1988); CNTF, 600 bp rat cDNA, gift of N. Y. Ip (Stlauockli et al., 1989); aFGF, 1,126 bp rat cDNA, gift of Dr. S. P. Goodrich; BDNF, 1,127 bp rat cDNA, gift of Dr. N. Y. Ip; IGF-1, 376 bp rat cDNA, gift of Dr. C. T. Roberts, Jr. (Lowe et al., 1988); FGFR 1 ( $f g$ ), 350 bp rat cDNA, gift of Dr. J. Milbrandt (Wanaka et al., 1990); CNTFR $\alpha, 600$ bp rat cDNA, gift of Dr. N. Y. Ip (Davis et al., 1991) trkB, 340 bp rat cDNA (extracellular domain), gift of Dr. N. Y. Ip; IGF$1 \mathrm{R}, 265$ bp rat cDNA, gift of Dr. C. T. Roberts, Jr. (Werner et al., 1989) GFAP, 2.6 kilo base (kb) rat cDNA, gift of Dr. R. K. H. Liem; and $18 \mathrm{~s}$ rRNA, $1.1 \mathrm{~kb}$ rat cDNA, gift of Dr. D. Schlessinger (Bowman et al., $1981)]$ were added to the hybridization buffer $\left(10^{6} \mathrm{cpm} / \mathrm{ml}\right)$ and hybridized at $50^{\circ} \mathrm{C}$ overnight. Blots were then washed twice in $2 \times \mathrm{SSC}$, $0.1 \%$ SDS at room temperature for $5 \mathrm{~min}$ and twice in $0.1 \times \mathrm{SSC}, 0.1 \%$ SDS at $65^{\circ} \mathrm{C}$ for $10 \mathrm{~min}$. After the posthybridization wash, blots were exposed to a Storage Phosphor Screen (Molecular Dynamics, Sunnyvale, $C A$ ) and data were digitized by scanning the phosphor screen with a Phosphor Imager System (Molecular Dynamics). Quantitative analysis of the digitized data was performed using Image Quant (Molecular Dynamics). The size of a given band was estimated by comparing the position of the band to the six bands of the 0.24-9.49 $\mathrm{kb}$ RNA ladder (GIBCO BRL, Gaithersburg, MD) in the same gel. Hard copies of blots were obtained by exposing blots to Hyper Film (Amersham). Blots were reprobed with an $18 \mathrm{~s}$ rRNA probe, and data of $18 \mathrm{~s}$ rRNA served as a control for RNA loading.

In situ hybridization. At designated times following injury, animals were killed by $\mathrm{CO}_{2}$ overdose and immediately perfused with phosphatebuffered saline (PBS), then $4 \%$ paraformaldehyde in $0.1 \mathrm{M}$ phosphate buffer, $\mathrm{pH}$ 7.4. Eyes were enucleated and the cornea and lens were removed. The rest of the eye was postfixed in $4 \%$ paraformaldehyde overnight, then in $30 \%$ sucrose in PBS for $4 \mathrm{hr}$. Eyes were embedded in Tissue-Tek O.C.T. compound (Miles Inc., Elkhart, IN), frozen in powdered dry ice, and stored at $-80^{\circ} \mathrm{C}$. Sections of $15-20 \mu \mathrm{m}$ were cut through the entire retina, along the vertical meridian and through the wound site, on a Cryostat at $-20^{\circ} \mathrm{C}$, and thaw mounted onto Super Frost Plus glass slides (Fisher Scientific, Pittsburgh, PA). Sections on the glass slides were air dried for $2 \mathrm{hr}$, fixed in $4 \%$ paraformaldehyde for $20 \mathrm{~min}$ prior to treatment with $10 \mu \mathrm{g} / \mathrm{ml}$ proteinase $\mathrm{K}$ for $10 \mathrm{~min}$ at $37^{\circ} \mathrm{C}$. Sections were then washed and treated with $0.25 \%$ acetic anhydride and $0.1 \mathrm{M}$ triethanolamine $(\mathrm{pH} 8.0)$ for $10 \mathrm{~min}, 0.1 \mathrm{M}$ Tris/ glycine buffer ( $\mathrm{pH} 7.0$ ) for $30 \mathrm{~min}$, and dehydrated in graded alcohols and then air dried. Sections were then hybridized with ${ }^{35} \mathrm{~S}$-labeled antisense RNA probe $\left(10^{7} \mathrm{cpm} / \mathrm{ml}\right)$ at $50^{\circ} \mathrm{C}$ over night. Some sections were hybridized with sense probe, which served as a control for nonspecific labeling (data not shown). The hybridization buffer contained $40 \%$ formamide, $4 \times \mathrm{SSC}, 1 \mathrm{mg} / \mathrm{ml}$ yeast $\mathrm{tRNA}, 1 \mathrm{mg} / \mathrm{ml}$ denatured salmon sperm DNA, $10 \%$ dextran sulfate, $10 \mathrm{~mm}$ DTT, and $5 \times$ Denhardt's solution. After hybridization, sections were washed twice in $2 \times$ SSC for $10 \mathrm{~min}$ at room temperature, once in $50 \%$ formamide, $2 \times \mathrm{SSC}$ at $52^{\circ} \mathrm{C}$ for $10 \mathrm{~min}$, and then were treated with RNase $\mathrm{A}(10 \mathrm{mg} / \mathrm{ml})$ in $2 \times \mathrm{SSC}$ for $10 \mathrm{~min}$ at room temperature. Sections were once again washed in $50 \%$ formamide, $2 \times \mathrm{SSC}$ for 10 min at $52^{\circ} \mathrm{C}$, then $2 \times \mathrm{SSC}$, $0.05 \%$ Triton X-100 for $1 \mathrm{hr}$ at room temperature. Finally, sections were dehydrated in graded alcohols and cleared in xylene. Slides were coated with NTB-3 photoemulsion (Eastman Kodak, Kochester NY), exposed at $4^{\circ} \mathrm{C}$ for $10-20 \mathrm{~d}$, and then developed.

\section{Results}

Injury-induced photoreceptor rescue in light-damaged rat retina

Seven days of constant light exposure damaged the retinas extensively. In the uninjured control rats, the outer nuclear layer (ONL) was reduced from its normal eight to nine rows of photoreceptor nuclei (Fig. $1 C$ ) to three to five rows in the equatorial region of the superior hemisphere (Fig. 1A,B). Moreover, the photoreceptor inner segments were almost totally destroyed and only small fragments of outer segments remained (Fig. $1 B$ ).

In the eyes injured by a knife wound, the injury differed from that shown previously by needle insertion (Faktorovich et al., 1992) by being longer (approximately $1 \mathrm{~mm}$ in length), by involving both the ONL and inner nuclear layer, and by the extrusion of some of the cells of these layers out the back of the eye in many cases (Fig. 2A). Like the needle-induced injury, however, the mechanical injury made in the present study resulted in photoreceptor rescue extending for a variable distance from the injury site (Fig. 2). As shown in Figure 2, the greatest degree of rescue occurred immediately adjacent to the injury site, where the ONL often comprised $80 \%$ of the normal number of photoreceptor nuclei (Fig. 2C). In these regions, photoreceptor inner segments were present, albeit shorter than normal, and a greater amount of outer segment membrane was present (Fig. $2 C$ ) than in regions further away from the injury site where there was little or no rescue (Fig. $2 B$ ), or in light-damaged, uninjured control eyes (Fig. $1 B$ ). The extent of rescue varied from several hundred micrometers (Fig. $2 A$ ) to more than half an eye, similar to previous results with a needle injury (Faktorovich et al., 1992).

\section{Increase in expression of bFGF and CNTF following injury}

Using Northern hybridization analysis, we determined the mRNA levels for five factors: bFGF, aFGF, CNTF, BDNF, and IGF-1 . Figure $3 A$ shows a representative Northern blot hybridized with probes complementary to mRNA encoding bFGF. A major transcript of $7.0 \mathrm{~kb}$ was detected in all samples. Quantitative data from three independent experiments are shown in Figure $3 B$. In the normal retinas, the expression of bFGF mRNA was relatively low (Fig. $3 A$, lane 1). A large increase of more than sixfold in bFGF mRNA was observed already at $12 \mathrm{hr}$ after injury. This increase reached a maximum of eightfold, at $2 \mathrm{~d}$ postinjury, and was still about fivefold elevated at day 10 . 


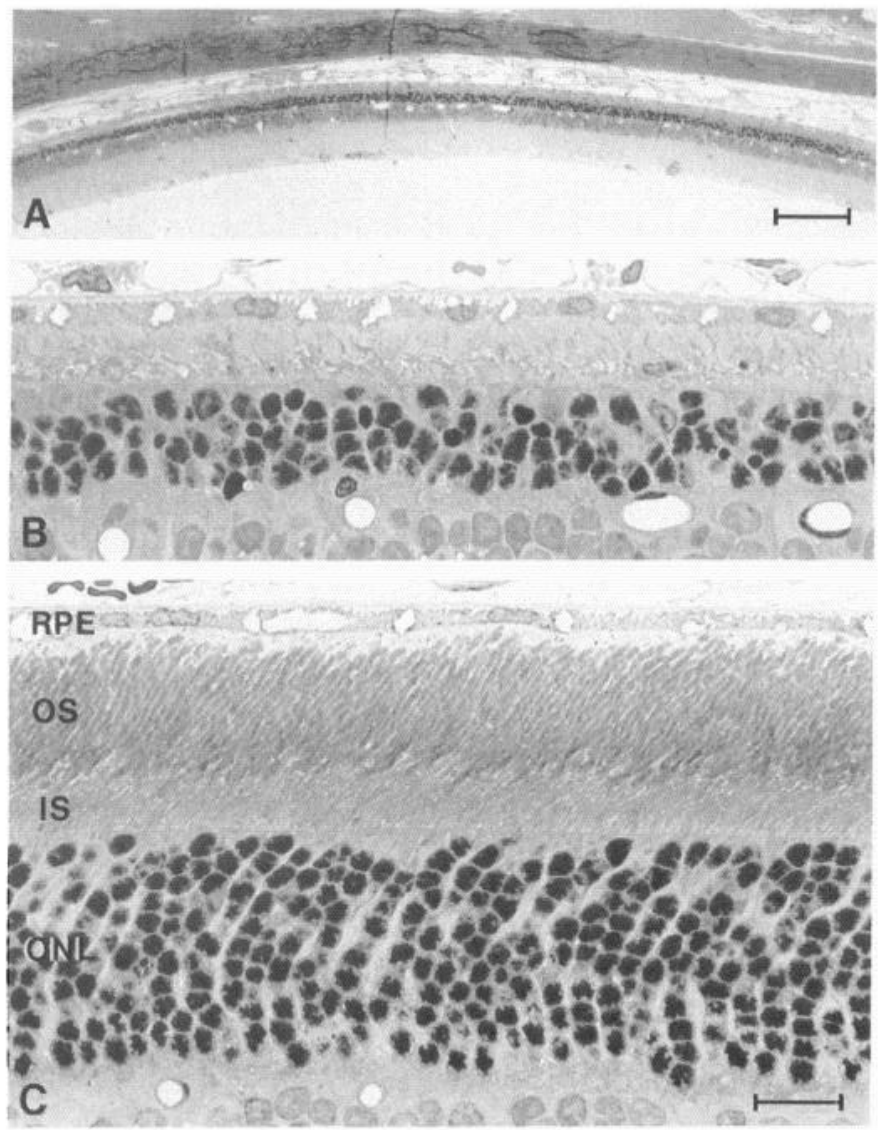

Figure 1. Light micrographs of retinas from Sprague-Dawley rats taken from the superior equatorial region of the eye. A, Control retina without mechanical injury exposed to $7 \mathrm{~d}$ of constant light. $B$, Higher magnification of a region of $A$ showing only three to five rows of surviving photoreceptor nuclei in the outer nuclear layer and almost no surviving inner and outer segments (compare to normal retina in $C$ ). $C$. Noninjured control retina of rat kept in cyclic light illustrating normal photoreceptor outer segments $(O S)$, inner segments $(I S)$, and outer nuclear layer $(O N L)$. RPE, retinal pigment epithelium. Toluidine blue stain. Scale bars: $A, 100 \mu \mathrm{m} ; C, 20 \mu \mathrm{m}$. Scale bar in $A$ applies to Figure $2 A$, as well, and scale bar in $C$ applies to Figs. $1 B, 2 B$, and $2 C$.

Using probes complementary to mRNA encoding CNTF, a band at $1.2 \mathrm{~kb}$ was detected. Along with it was a less abundant band at $3.5 \mathrm{~kb}$ (Fig. $4 A$ ). This $3.5 \mathrm{~kb}$ band was found to be polyadenylated, but the precise function of this transcript or its relationship to CNTF remains unknown (Rudge et al., 1991). Figure $4 B$ shows quantitative data for CNTF mRNA from the $1.2 \mathrm{~kb}$ bands. There was a 1.7 -fold increase in CNTF mRNA $12 \mathrm{hr}$ postinjury, compared to normal control. The upregulation of CNTF mRNA reached a maximum of threefold on day 4, then declined to about 1.8-fold on day 10 .

We also examined the expression of the other three factors: aFGF, BDNF, and IGF-1. Unlike bFGF or CNTF, there was little change in either aFGF or IGF-1 mRNA expression after injury (not shown). Expression of BDNF mRNA, however, showed a small decrease (about $20 \%$ by day 7 , and $30 \%$ by day 10 ) following injury (not shown). A similar decrease in BDNF mRNA was found in the brain after an aspiration lesion of dorsal hippocampus and overlying cortex (Ip et al., 1993).

Increase in expression of FGFRI following injury

We next assessed the expression of mRNAs for FGFR1, $\mathrm{CNTFR} \alpha, \operatorname{trkB}$, and IGF-1R in normal and injured retinas.
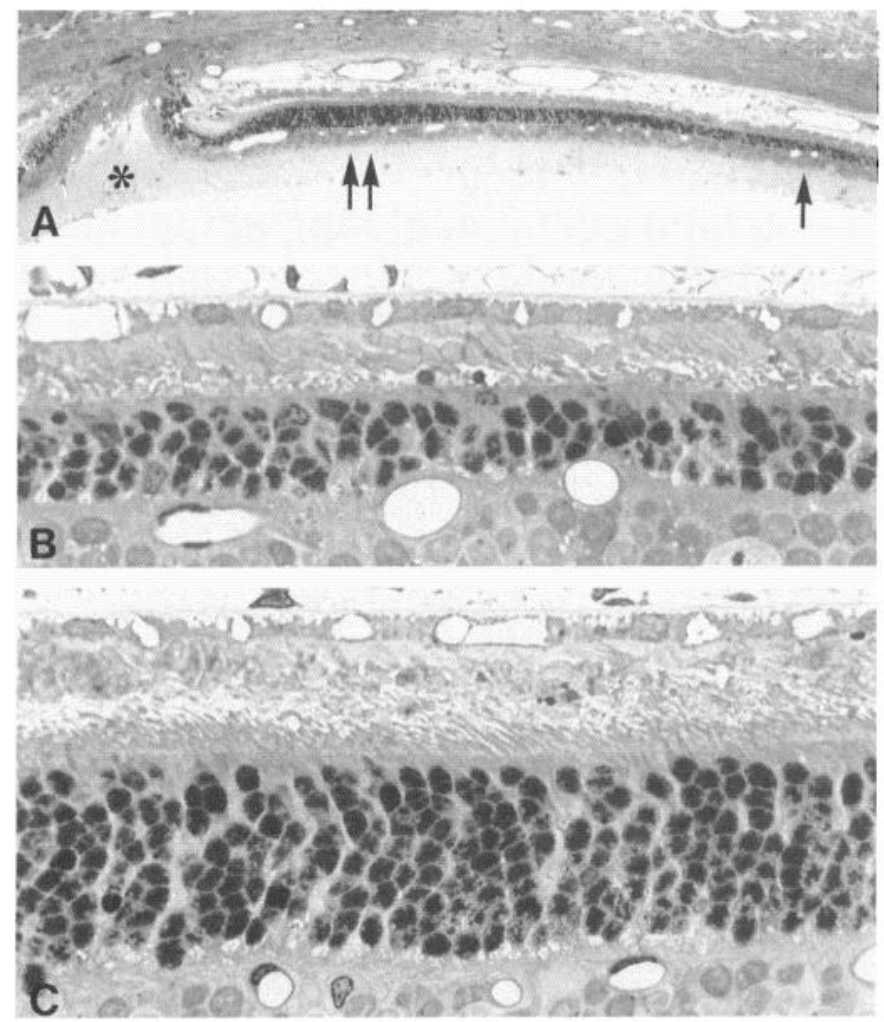

Figure 2. Light micrographs of a retina with mechanical injury from a rat exposed to $7 \mathrm{~d}$ of constant light. $A$, Superior equatorial region of the eye, comparable to that shown for a control retina in Figure $1 A$. The ONL immediately adjacent to the injury site $(*)$ is substantially thicker (double arrows) than farther away from the lesion (single arrow), indicating a significantly greater degree of photoreceptor rescue closer to the injury site. $B$, Higher magnification of the region shown by the single arrow in $A$ (taken from a serial section). Little, if any, rescue is present in this region based on comparison with the control retina in Figure $1 B$. C , Higher magnification of the region shown by the double arrows in A. About $75-80 \%$ of the photoreceptor nuclei are present in the ONL (compare with Fig. $1 C$ ). There are also significantly longer inner segments and a greater abundance of outer-segment membranes are present than distant from the injury site as shown in $B$. Toluidine blue stain. Magnification bars shown in Figure 1.

Northern hybridization using probes complementary to mRNA encoding FGFR1 detected a single band at $4.3 \mathrm{~kb}$ (Fig. 5A). Figure $5 B$ shows quantitative data from three independent experiments. The response of FGFR 1 mRNA to injury was immediate and transient: there was a threefold increase in FGFR 1 mRNA only $12 \mathrm{hr}$ after injury, which then slowly declined towards the baseline over a period of $10 \mathrm{~d}$.

There was virtually no change in the expression of CNTFR $\alpha$, trkB, or IGF-1R from the control levels throughout the $10 \mathrm{~d}$ postinjury period (not shown).

\section{Upregulation of GFAP expression following injury}

To assess the glial cell response to injury, we examined the expression of GFAP mRNA. Northern blots hybridized using probes complementary to mRNA encoding GFAP showed a single band at $2.8 \mathrm{~kb}$ in all lanes (Fig. 6A). Quantitative data from three independent experiments are shown in Figure $6 B$. The expression of GFAP mRNA was relatively low in the normal control. Following injury, there was an immediate increase (close to sixfold, by $12 \mathrm{hr}$ postinjury), which reached a peak of about 

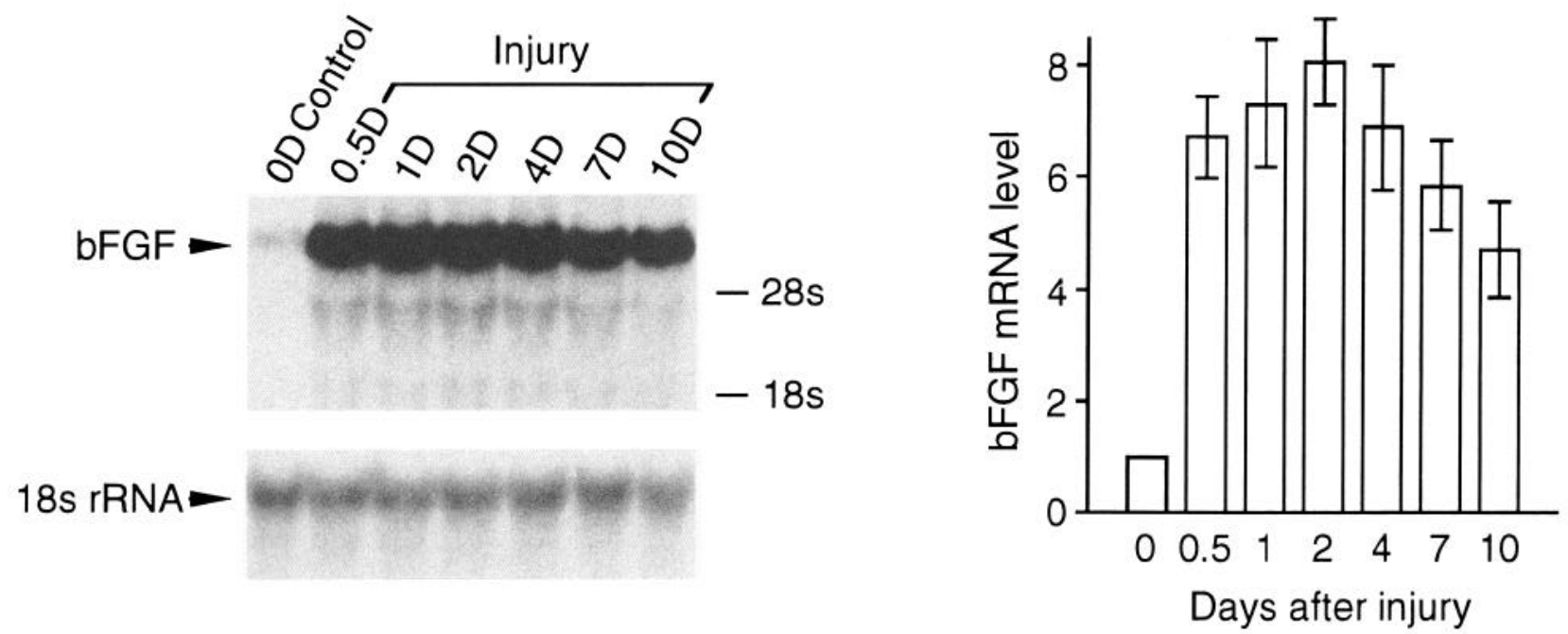

Figure 3. Expression of bFGF mRNA in the retina after mechanical injury. A, Northern blot hybridization with probes complementary to mRNA encoding bFGF. Total RNA ( $20 \mu \mathrm{g} / \mathrm{lane})$ was isolated from pooled retinas at various times postinjury, and electrophoresed in $1 \%$ formaldahyde denaturing gel. Retinas without injury served as controls. A major bFGF transcript of $7.0 \mathrm{~kb}$ was detected in all lanes (indicated at left). Migration of $28 \mathrm{~s}$ and $18 \mathrm{~s}$ rRNA is indicated at the right (upper panel). The same blot was then stripped of the bFGF probes and rehybridized with probes for 18s rRNA, which served as a control for RNA loading (lower panel). The time after injury, in days, is indicated on top of each lane. B, Quantification of relative bFGF mRNA levels. The intensity of the $7.0 \mathrm{~kb}$ transcript was digitized and quantified by using a Phosphor Image System, and then normalized to the intensity of $18 \mathrm{~s}$ rRNA. Data from three independent experiments were averaged and presented as relative to the control level (Mean $\pm \mathrm{SD}, n=3)$.

ninefold $2 \mathrm{~d}$ postinjury, and then declined to a fivefold level at day 10. Thus, the time course of GFAP expression following injury is similar to that of bFGF.

\section{Localization of bFGF, CNTF, and GFAP mRNAs}

We performed in situ hybridizations to localize sites of bFGF, CNTF, and GFAP upregulation in the retina. Figure 7 shows photomicrographs of hybridizations with an antisense RNA probe for bFGF in injured (Fig. 7A-D) and normal retinas (Fig. $7 E-F)$. In both injured and normal retinas, bFGF mRNAs were found in the retinal pigment epithelial cells, the inner nuclear layer, the ganglion cell layer, and also in the layer that corresponds to the inner segments of photoreceptors (Fig. $7 F$ ). After injury, there was a marked increase in the intensity of bFGF signal in each of the layers in the vicinity of the wound (Fig. $7 B$ ), including the inner segments of photoreceptors and retinal pigment epithelium. However, the greatest increase was found in the inner nuclear layer. This increase declined with distance from the wound, as shown in Fig. 7D. The increase in bFGF mRNA in the pigment epithelium following injury may suggest its possible involvement in the response to injury.

Photomicrographs of in situ hybridizations with an RNA probe for CNTF are shown in Figure 8. Expression of CNTF mRNA was at a very low level in the inner nuclear layer and ganglion cell layer in the normal control (Fig. 8F). After injury, intense CNTF mRNA signal was seen in the inner nuclear layer in the area adjacent to the wound site (Fig. $8 B$ ). The upregulation of CNTF mRNA rapidly declined with distance from the wound (Fig. 8D).

Figure 9 shows photomicrographs of in situ hybridizations with an antisense RNA probe for GFAP. In the normal control, weak GFAP labeling was present in the inner nuclear layer and ganglion cell layer (Fig. 9F). A sharp increase in GFAP signal was evident in both layers in the superior retina where a wound was made (Fig. 9D). In the inferior retina, which was distant from the wound of the injured eye, strong GFAP mRNA signal was seen in the ganglion cell layer, but in the inner nuclear layer, the signal was far less pronounced (Fig. 9D) than near the wound (Fig. 9B).

\section{Discussion}

The rat retina exhibits a remarkable self-protective mechanism that enhances photoreceptor survival. Local injury, before the onset of, or during a retinal degeneration, protects photoreceptors near the wound from degenerating. It is a unique demonstration that injury to neuronal tissue slows or even stops a neuronal degeneration (Faktorovich et al., 1990, 1992; Silverman and Hughes, 1990; Blair et al., 1991; Li et al., 1991).

Rescue of photoreceptors by injury resembles in some ways the "conditioning lesion" effect in the brain and the peripheral nervous system where an initial (conditioning) lesion facilitates recovery from a subsequent (test) lesion, compared to the recovery following only a single lesion (McQuarrie et al., 1977; Nieto-Sampedro et al., 1984; Perez-Polo et al., 1990). Injuryinduced synthesis and secretion of neurotrophic factors are believed to be responsible for the conditioning lesion effects (Nieto-Sampedro and Cotman, 1985). Indeed, mechanical injury to the brain has been found to increase both bFGF immunoreactivity and its mRNA level (Finklestein et al., 1988; Frautschy et al., 1991; and Logan et al., 1992), with an increase in the total mitogenic activity of heparin-binding proteins extracted from lesioned cerebral hemispheres (Logan et al., 1992). A remarkable increase in CNTF mRNA and CNTF-like neurotrophic activity were also observed in the rat brain following an aspiration lesion (Ip et al., 1993). Our findings that mechanical injury upregulates bFGF and CNTF mRNAs in the retina are consistent with evi- 
A.

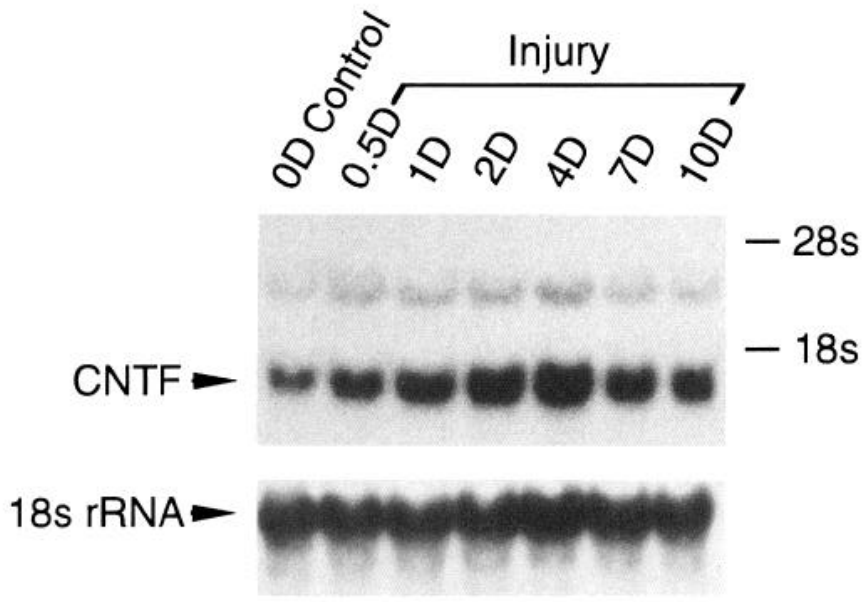

B.

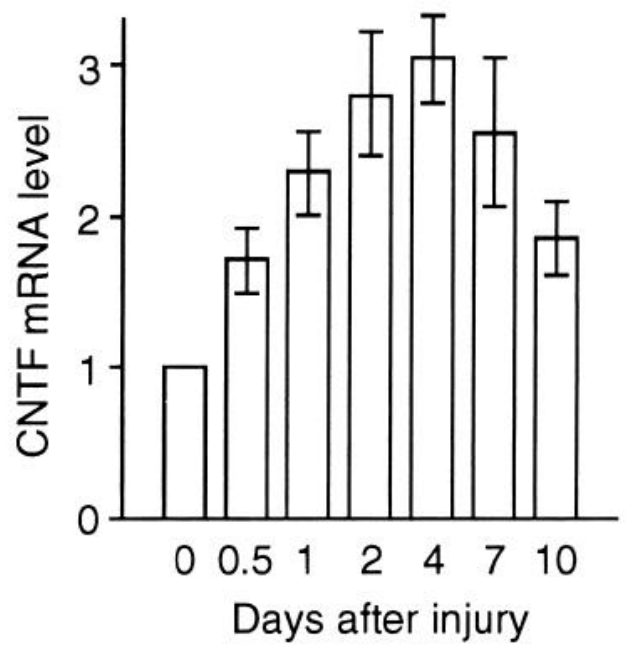

Figure 4. Expression of CNTF mRNA in the retina after injury. A, Northern blot hybridization with probes complementary to mRNA encoding CNTF. Total RNA $(20 \mu \mathrm{g} / \mathrm{lane})$ was isolated from pooled retinas at various times postinjury, and electrophoresed in $1 \%$ formaldahyde denaturing gel. Retinas without injury served as controls. CNTF transcript was detected as a band of $1.2 \mathrm{~kb}$ (indicated at left). A minor band of $3.5 \mathrm{~kb}$, whose relation to CNTF was unknown (see text for detail), was also observed. Migration of $28 \mathrm{~s}$ and 18s rRNA is indicated at the right (upper panel). The same blot was then stripped and rehybridized with probes for 18s rRNA, which served as a control for RNA loading (lower panel). The time after injury is indicated, in days, on top of each lane. B, Quantification of relative CNTF mRNA levels. The intensity of the $1.2 \mathrm{~kb}$ transcript was digitized and quantified by using a Phosphor Image System, and then normalized to the intensity of $18 \mathrm{~s}$ rRNA. Data from three independent experiments were averaged and presented as relative to the control level (Mean $\pm \mathrm{SD}, n=3$ ).

dence from the brain, and imply that this injury response is common to CNS tissues.

In the retina, the increase in bFGF mRNA after injury was prompt and great in amplitude, while the response of CNTF mRNA was relatively slower and smaller. For both bFGF and CNTF mRNAs, the elevation lasted at least $10 \mathrm{~d}$, the entire period we studied. The differences in the amplitudes of mRNA expression and the temporal patterns for the two factors suggests functional differences in their contributions to the injury response in the retina.

Our results of in situ hybridization show that the elevation of both bFGF and CNTF mRNAs was concentrated near the wound

A.

B.
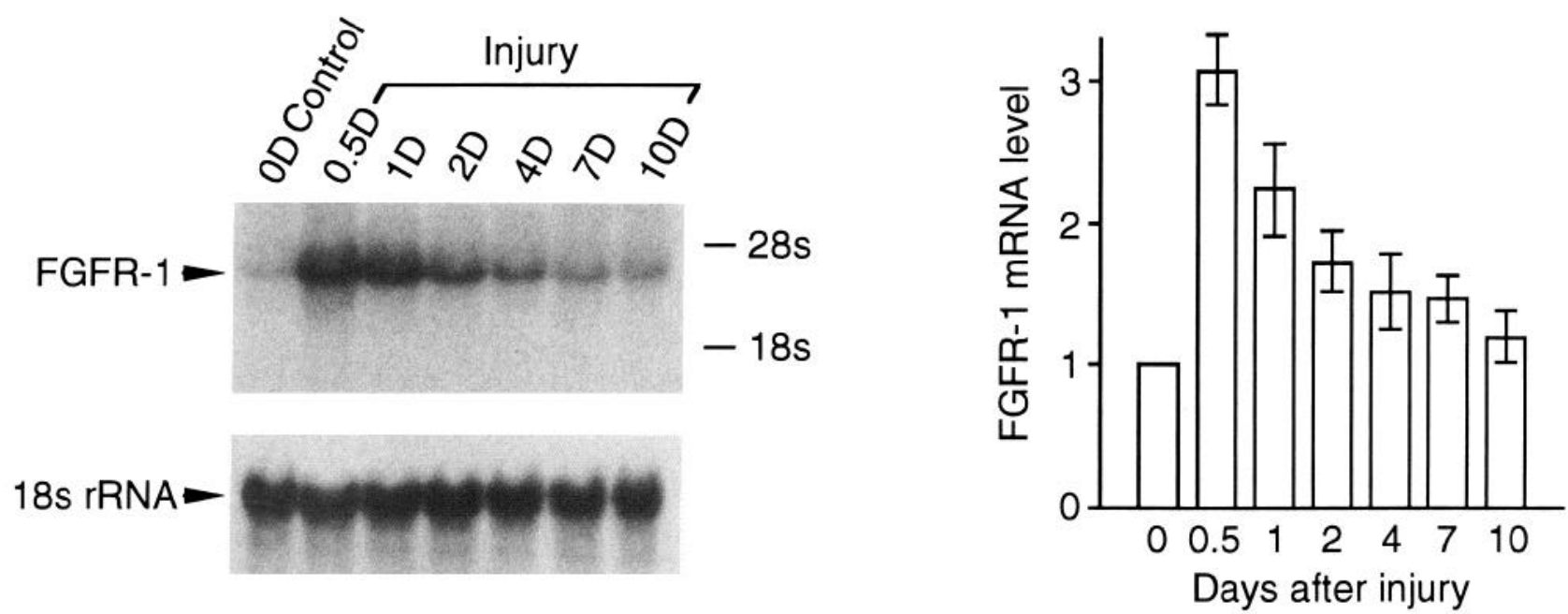

Figure 5. Expression of FGFR1 mRNA in the retina after injury. A, Northern blot hybridization with probes complementary to mRNA encoding FGFR1. Total RNA $(20 \mu \mathrm{g} / \mathrm{lane})$ was isolated from pooled retinas at various times postinjury, and electrophoresed in $1 \%$ formaldahyde denaturing gel. Retinas without injury served as controls. FGFR1 transcript was detected as a band of $4.3 \mathrm{~kb}$ (indicated at left). Migration of $28 \mathrm{~s}$ and $18 \mathrm{~s}$ rRNA is indicated at the right (upper panel). The same blot was then stripped and rehybridized with probes for 18s rRNA, which served as a control for RNA loading (lower panel). The time after injury is indicated, in days, on top of each lane. B, Quantification of relative FGFR1 mRNA levels. The intensity of the $4.3 \mathrm{~kb}$ transcript was digitized and quantified by using a Phosphor Image System, and then normalized to the intensity of $18 \mathrm{~s}$ rRNA. Data from three independent experiments were averaged and presented as relative to the control level $($ Mean \pm SD, $n=3)$. 
A.

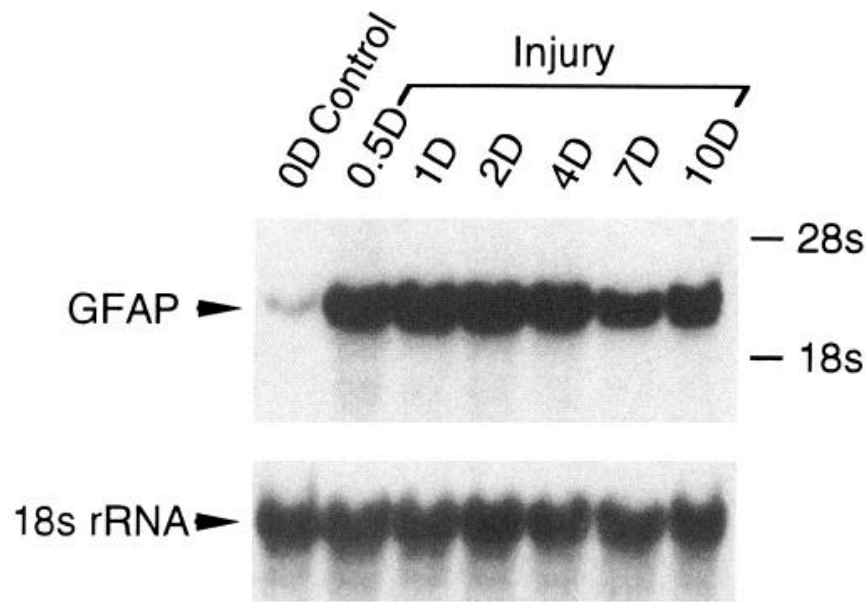

B.

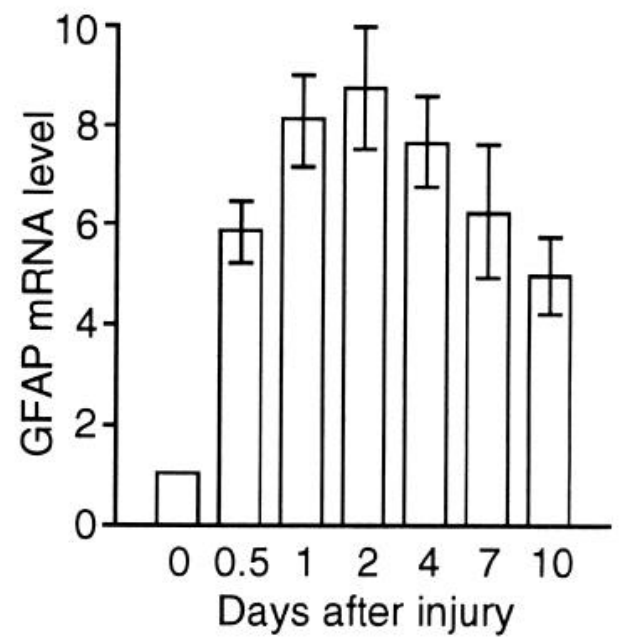

Figure 6. Expression of GFAP mRNA in the retina after injury. A, Northern blot hybridization with probes complementary to mRNA encoding GFAP. Total RNA $(20 \mu \mathrm{g} / \mathrm{lane})$ was isolated from pooled retinas at various times postinjury, and electrophoresed in $1 \%$ formaldahyde denaturing gel. Retinas without injury served as controls. GFAP transcript was detected as a band of $2.8 \mathrm{~kb}$ (indicated at left). Migration of $28 \mathrm{~s}$ and $18 \mathrm{~s}$ rRNA is indicated at the right (upper panel). The same blot was then stripped and rehybridized with probes for 18s rRNA, which served as a control for RNA loading (lower panel). The time after injury is indicated, in days, on top of each lane. $B$, Quantification of relative GFAP mRNA levels. The intensity of the $2.8 \mathrm{~kb}$ transcript was digitized and quantified by using a Phosphor Image System, and then normalized to the intensity of $18 \mathrm{~s}$ rRNA Data from three independent experiments were averaged and presented as relative to the control level (Mean $\pm \operatorname{SD}, n=3$ ).

and declined with distance from it. This coincides with the photoreceptor protective effect of mechanical injury in both RCS and light-damaged rats, which was at its peak close to the wound site and declined with distance from the wound (Faktorovich et al., 1990, 1992). This spatial coincidence of factor and protection suggests that these endogenous factors are directly involved in protecting photoreceptors.
Although aFGF, BDNF, and IGF-1 also have been shown to protect photoreceptors when injected into the eye (LaVail et al., 1992), we failed to observe significant alterations in aFGF and IGF-1 mRNA expression following injury, while BDNF mRNA showed a small decrease after injury. The absence of significant change in these three factors indicates that they are probably not injury-responsive factors, and are therefore unlikely to partici-
Figure 7. Localization of bFGF mRNA in the normal and injured retinas. In situ hybridization was carried out using a bFGF antisense RNA probe. Photomicrographs of Nomarski and dark-field images of same sections are shown in $A, C$, and $E$, and $B, D$, and $F$, respectively. $A$ and $B$, A section of the superior retina close to the lesion site (the lesion was to the right of the section) $2 \mathrm{~d}$ postinjury. $C$ and $D$, A section of the inferior retina from the same eye of $A$ and $B . E$ and $F$, A section of the superior retina of a normal control eye. Note the marked increase in bFGF mRNA in the superior retina near the lesion, especially in the inner nuclear layer (in) $(B)$, while the labeling of bFGF mRNA declined in the inferior retina $(D)$, which was distant from the lesion. There were only weak signals of bFGF mRNA in the normal control (E). Scale bar: $100 \mu \mathrm{m}$; same magnification for all photomicrographs. Abbreviations: $p e$, pigment epithelium; on, outer nuclear layer; in, inner nuclear layer; $g c$, ganglion cell layer.
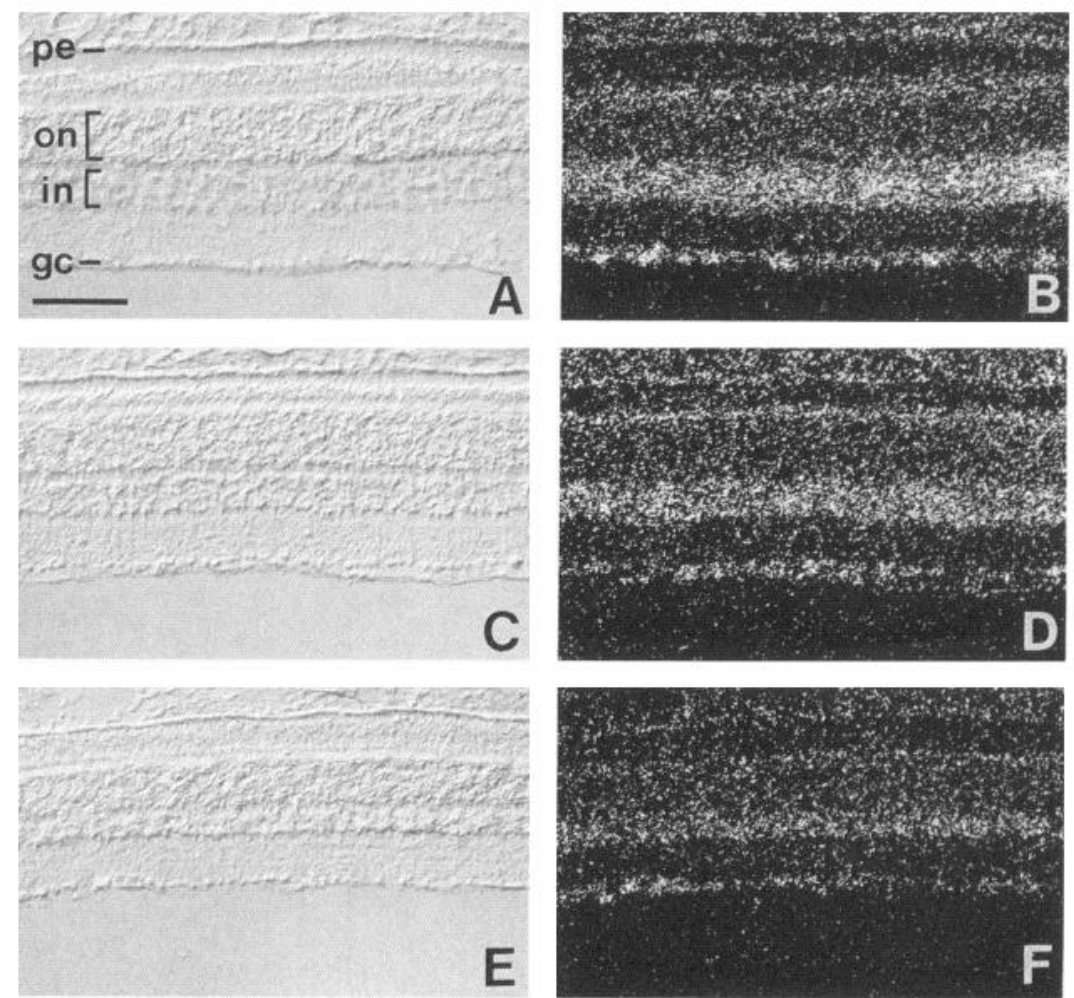

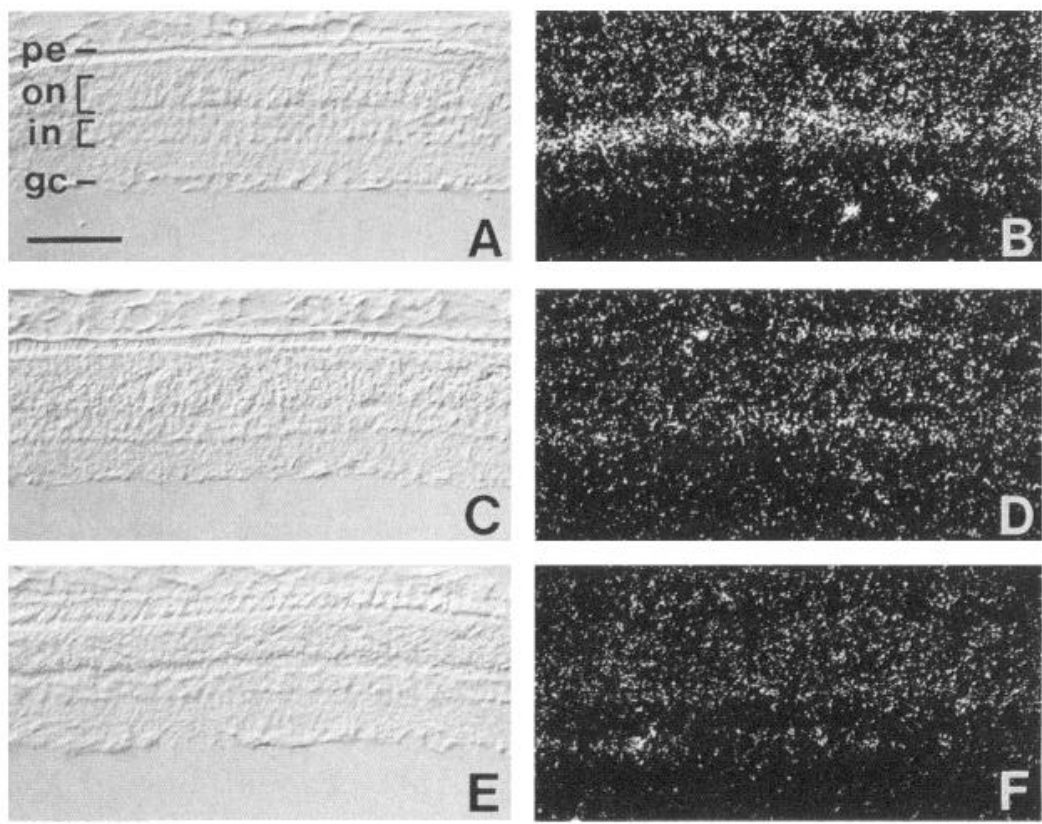

Figure 8. Localization of CNTF mRNA in the normal and injured retinas. In situ hybridization was carried out using a CNTF antisense RNA probe. Photomicrographs of Nomarski and dark-field images of same sections are shown in $A, C$, and $E$, and $B, D$, and $F$, respectively. $A$ and $B$, A section of the superior retina close to the lesion site (the lesion was to the right of the section) 2 d postinjury. $C$ and $D$, A section of the inferior retina from the same eye of $A$ and $B$. E and $F$, A section of the superior retina of a normal control eye. Note the marked increase in CNTF mRNA in the inner nuclear layer (in) near the lesion $(B)$, while the labeling of CNTF mRNA in the inner nuclear layer sharply decreased in the inferior retina $(D)$, which was distant from the lesion. There were very weak signals for CNTF mRNA in the normal control (E). Scale bar: $100 \mu \mathrm{m}$; same magnification for all photomicrographs. Abbreviations: $p e$, pigment epithelium; on, outer nuclear layer; in, inner nuclear layer; $g c$, ganglion cell layer. pate in the injury-induced photoreceptor rescue. The decrease in BDNF mRNA is consistent with the similar findings in the brain (Ip et al., 1993) and remains unexplained.

Among the receptors, only FGFR-1 mRNA showed a fast and transient elevation. The initial increase of FGFR1 mRNA is correlated with the upregulation of one of its ligands, bFGF, suggesting a correlated regulation of the two genes by injury, which may be important in promoting photoreceptor survival in the retina. Increase in FGFR-1 mRNA was also observed in the brain after injury (Logan et al., 1992). Due to the low expression level of FGFR1 in the retina, however, we failed to localize its expression.

GFAP is a glial cell-specific intermediate filament protein whose elevated expression is widely used as an indicator of glial cell response to neuronal injury (Hatten et al., 1991). In mammalian retina, GFAP is normally found in astrocytes, while its upregulation was observed in the Müller cells after retinal injury, degeneration, or detachment (Bignami and Dahl, 1979; Miller and Oberdorfer, 1981; Shaw and Weber, 1983; Eisenfild et al., 1984; Erickson et al., 1987). We found a rapid upregulation of
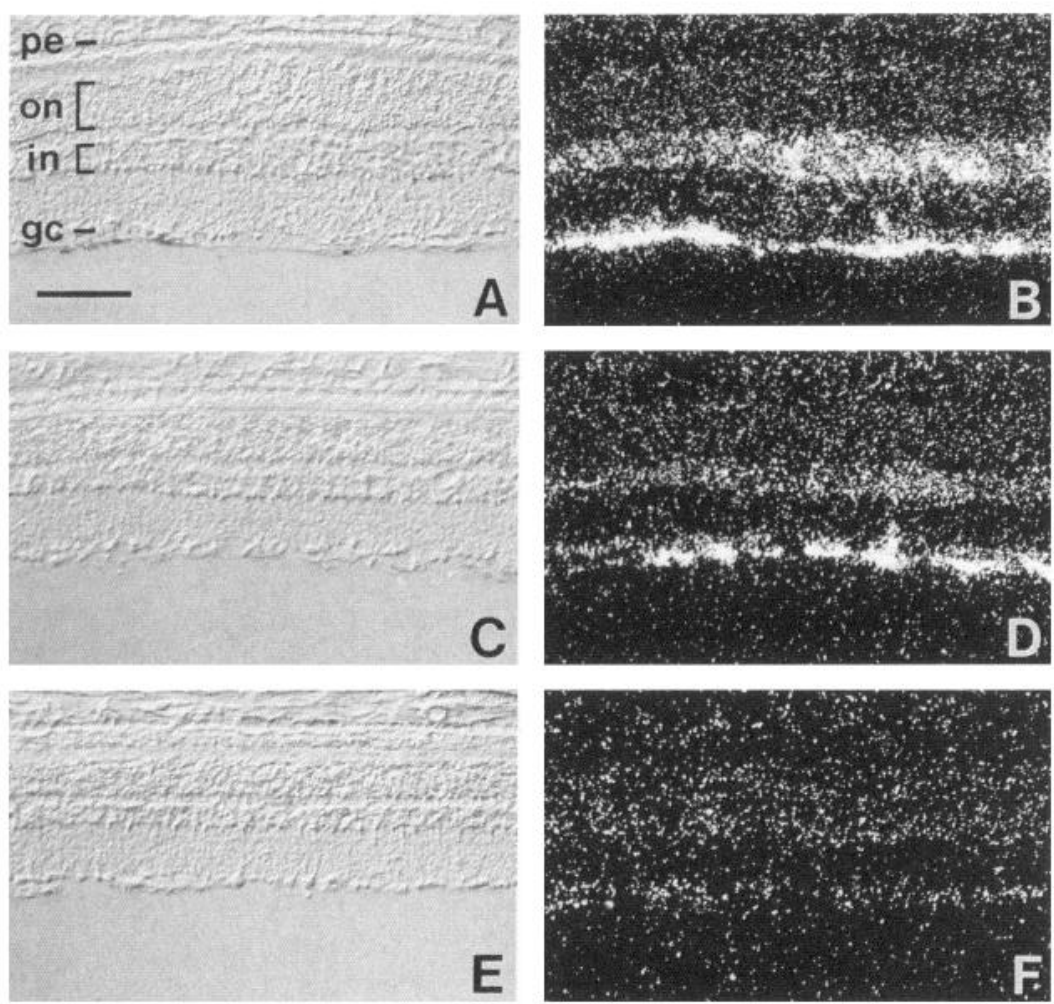

Figure 9. Localization of GFAP mRNA in the normal and injured retinas. In situ hybridization was carried using a GFAP antisense RNA probe. Photomicrographs of Nomarski and dark-field images of same sections are shown in $A, C$, and $E$, and $B, D$, and $F$, respectively. $A$ and $B$, A section of the superior retina close to the lesion site (the lesion was to the right of the section) $2 \mathrm{~d}$ postinjury. $C$ and $D$, A section of the inferior retina from the same eye of $A$ and $B . E$ and $F$, A section of the superior retina of a normal control eye. Note the marked increase in GFAP mRNA in the inner nuclear layer (in) and the ganglion cell layer $(g c)$ near the lesion $(B)$, while the signals declined in the inferior retina, which was distant from the lesion, especially in the inner nuclear layer $(D)$. There were some weak signals for GFAP mRNA in both layers of the normal control $(E)$. Scale bar: $100 \mu \mathrm{m}$; same magnification for all photomicrographs. Abbreviations: pe, pigment epithelium; on, outer nuclear layer; in, inner nuclear layer; $g c$, ganglion cell layer. 
GFAP mRNA after retinal injury with a time course quite similar to that of bFGF. In situ hybridization showed that GFAP mRNA increased in the inner nuclear laycr and the ganglion ccll and nerve fiber layers, consistent with it being expressed by Müller cells in the inner nuclear layer and astrocytes in the ganglion cell and nerve fiber layers.

Increases in bFGF and CNTF mRNAs after injury were mainly found in the inner nuclear layer near the wound site, similar to the location where GFAP signals were observed. These findings suggest that activated Müller cells play a major role in response to retinal injury, perhaps by producing survival factors such as bFGF and CNTF.

The present work represents a step toward achieving a better understanding of the mechanism of injury-induced photoreceptor protection in the retina. Further studies are in progress to investigate the expression and distribution of bFGF and CNTF proteins in response to injury, and the possible involvement of other survival factors and their receptors. The neuroprotective activities of bFGF and CNTF have been well described (see reviews by Wagner, 1991; Baird, 1994, for bFGF; Manthorpe et al., 1993, for CNTF). In the retina, exogenous bFGF or CNTF, when injected into the eye, protects photoreceptors from degenerating in RCS and light-damaged rats (Faktorovich et al., 1990, 1992; LaVail et al, 1992). Moreover, the induction of endogenous bFGF in the retina by optic nerve crush (Kostyk et al., 1994 ) is believed to be, at least in part, responsible for photoreceptor rescue in light-damaged rats (Bush and Williams, 1991). Clearly, the evidence for spatial and temporal changes in bFGF and CNTF mRNAs that correlate with photoreceptor protection strongly suggests that these two factors mediate photoreceptor rescue induced by mechanical injury, and that Müller cells play a central role in the mechanism of injury rescue.

\section{References}

Baird A (1994) Fibroblast growth factors: activities and significance of non-neurotrophin neurotrophic growth factors. Curr Opin Neurobiol 4:78-86.

Bignami A, Dahl D (1979) The radial glia of Müller in the rat retina and their response to injury. An immunofluorescence study with antibodies to the glial fibrillary acidic (GFA) protein. Exp Eye Res 28: 63-69.

Blair JR, Gaur V, Laedtke TW, Li L, Liu Y, Sheedlo H, Yamaguchi K, Turner JE (1991) In oculo transplantation studies involving the neural retina and its pigment epithelium. In: Progress in retinal research, Vol 10 (Osborne N, Chader G, eds), pp 69-88. Oxford: Pergamon.

Rowman I.H, Rahin B, Schlessinger D (1981) Multiple ribosomal RNA cleavage pathways in mammalian cells. Nucleic Acids Res 9:49514966.

Bush RA, Williams TP (1991) The effect of unilateral optic nerve section on retinal light damage in rats. Exp Eye Res 52:139-153.

Danias J, Stylianopoulou F (1990) Expression of IGF-I and IGF-II genes in the adult rat eye. Curr Eye Res 9:379-386.

Davis S, Aldrich TH, Valenzuela DM, Wong V, Furth ME, Squinto SP, Yancopoulos GD (1991) The receptor for ciliary neurotrophic factor Science 253:59-63.

Eisenfild AJ, Bunt-Milam AH, Sarthy PV (1984) Müller cell expression of glial fibrillary acidic protein after genetic and experimental photoreceptor degeneration in the rat retina. Invest Ophthalmol Vis Sci 25:1321-1328.

Erickson PA, Fisher SK, Guérin C.I, Anderson DH, Kaska DD (1987) Glial fibrillary acidic protein increases in Müller cells after retinal detachment. Exp Eye Res 44:37-48.

Faktorovich EG, Steinberg RH, Yasumura D, Matthes, MT, LaVail, MM (1990) Photoreceptor degeneration in inherited retinal dystrophy delayed by basic fibroblast growth factor. Nature 347:83-86.

Fakturuvich EG, Steinberg RH, Yasumura D, Matthes, MT, LaVail, MM (1992) Basic fibroblast growth factor and local injury protect photoreceptors from light damage in the rat. J Neurosci 12:3554-3567.
Farrell ER (1993) RNA methodologies: a laboratory guide for isolation and characterization. San Diego: Academic.

Finklestein SP, Apostolides PJ, Caday CG, Prosser J, Philips MF, Klagsbrun M (1988) Increased basic fibroblast growth factor (bFGF) immunoreactivity at the site of focal brain wounds. Brain Res 460:253259.

Frautschy SA, Walicke pA, Baird A (1991) Localization of basic fibroblast growth factor and its mRNA after CNS injury. Brain Res 553:291 299.

Garcia-Estroda J, Garcia-Segura LM, Torres-Aleman I (1992) Expression of insulin-like growth factor I by astrocytes in response to injury. Brain Res 592:343-347.

Hatten ME, Liem RKH, Shelanski ML, Mason CA (1991) Astroglia in CNS injury. Glia 4:233-243.

Hicks D, Bugra K, Faucheux B, Jeanny J-C, Laurent M, Malecaze F, Mascarelli F, Raulais, D, Cohen Y, Courtois Y (1991) Fibroblast growth factors in the retina. In: Progress in retinal research, Vol 11 (Osborne N, Chader G, eds), pp 333-374. Oxford: Pergamon.

Ip NY, Wiegand SJ, Morse J, Rudge JS (1993) Injury-induced regulation of ciliary ncurotrophic factor mRNA in the adult rat brain. Eur J Neurosei 5:25-33.

Kirsch M, Grünert U, Hofmann H-D (1993) Ciliary neurotrophic factor and its receptor in the rat retina. Soc Neurosci Abstr 19:251.

Kostyk SD, D'Amore PA, Herman IM, Wagner JA (1994) Optic nerve injury alters basic fibroblast growth factor localization in the retina and optic tract. J Neurosci 14:1441-1449.

LaVail MM, Battelle B-A (1975) Influence of eye pigmentation and light deprivation on inherited retinal dystrophy in the rat. Exp Eye Res 21:167-192.

LaVail MM, Unoki K, Yasumura D, Matthes MT, Yancopoulos GD, Steinberg RII (1992) Multiple growth factors, cytokines, and neurotrophins rescue photoreceptors from the damaging effects of constant light. Proc Natl Acad Sci USA 89:11249-11253.

Li L, Sheedlo HJ, Gaur V, Turner JE (1991) Effects of macrophage and retinal pigment epithelial cell transplants on photoreceptor cell rescue in RCS rats. Curr Eye Res 10:947-958.

Logan A, Frautschy SA, Gonzalez A-M, Baird A (1992) A time course for the focal elevation of synthesis of basic fibroblast growth factor and one of its high-affinity receptors $(f g$ ) following a localized cortical brain injury. J Neurosci 12:3828-3837.

Lowe WLJ, Lasky, SR, LeRoith D, Roberts CTJ (1988) Distribution and regulation of rat insulin-like growth factor I messenger ribonucleic acids encoding alternative carbox yterminal E-peptides: evidence for differential processing and regulation in liver. Mol Endocrinol 2:528-535.

Mansour-Robaey S, Clarke DB, Wang Y-C, Bray GM, Aguayo AJ (1994) Effects of ocular injury and the administration of brain-derived neurotrophic factor (BDNF) on the survival and regrowth of axotomized retinal ganglion cells. Proc Natl Acad Sci USA 91:1632 1636.

Manthorpe M, Louis J-C, Hagg T, Varon S (1993) Ciliary neurotrophic factor. In: Neuronotrophic factors (Fallon J, Laughlin S, eds), pp 443 471. San Diego: Academic.

McQuarrie IG, Grafstein B, Gershon MD (1977) Axonal regeneration in the rat sciatic nerve: effect of a conditioning lesion and of dbcAMP. Brain Res 132:443-453.

Miller NM, Oberdorfer M (1981) Neuronal and neuroglial responses following reitnal lesions in the neonatal rats. J Comp Neurol 202: 493-504.

Nieto-Sampedro M, Cotman CW (1985) Growth factor induction and temporal order in central nervous system repair. In: Synaptic plasticity (Cotman CW ed), pp 407-455. New York: Guilford.

Nieto-Sampedro M, Whittemore SR, Needels DL, Larson J, Cotman CW (1984) Survival of brain transplants is enhanced by extracts from injured brain. Proc Natl Acad Sci USA 81:6250-6254.

Nieto-Sampedro M, Lim R, Hicklin DJ, Cotman CW (1988) Early release of glia maturation factor and acidic fibroblast growth factor after rat brain injury. Neurosci Lett 86:361-365.

Perez-Polo JR, Foreman PJ, Jackson GR, Shan D. Taglialatela G, Thorpe LW, Werrbach-Perez K (1990) Nerve growth factor and neuronal cell death. In: Molecular neurobiology (Bazan NG, ed), pp 5790. Clifton, NJ: Humana.

Robbins E, Figueroa D, Bozyczko-Coyne D, McKenna BW, Contreras P (1993) Recombinant human insulin-like growth factor-1 (rhIGF- 
1) increases the survival of photoreceptor cells (PRCs) during retinal degeneration in the RCS rats. Soc Neurosci Abstr 19:659.

Rudge JS, Alderson RF, Pasnikowski E, McClain J, Ip NY, Lindsay RM (1991) Expression of ciliary neurotrophic factor and the neurotrophins-nerve growth factor, brain-derived neurotrophic factor and neurotrophin 3-in cultured rat hippocampal astrocytes. Eur J Neurosci 4:459-471.

Shaw G, Weber K (1983) The structure and development of the rat retina: an immunofluorescence microscopical study using antibodies specific for intermediate filament proteins. Eur J Cell Biol 30:219232.

Shimasaki S, Emoto N, Koba A, Mercado M, Shibata F, Cooksey K, Baird A, Ling N (1988) Complementary DNA cloning and sequencing of rat ovarian basic fibroblast growth factor and tissue distribution study of its mRNA. Biochem Biophys Res Commun 157:256-263.

Silverman MS. Hughes SE (1990) Photoreceptor rescue in the RCS rat without pigment epithelium transplantation. Curr Eye Res 9:183-191.
Steinberg RH (1994) Survival factors in retinal degenerations. Curr Opin Neurobiol 4:515-524.

Stöckli KA, Lottspeich F, Sendtner M, Masiakowski P, Carroll P, Götz R, Lindholm D, Thoenen H (1989) Molecular cloning, expression and regional distribution of rat ciliary neurotrophic factor. Nature 342:920-923.

Wagner JA (1991) The fibroblast growth factors: an emerging family of neural growth factors. Curr Top Microbiol Immunol 165:95-118.

Wanaka A, Johnson EM Jr, Milbrant J (1990) Localization of FGF receptor mRNA in the adult rat central nervous system by in situ hybridization. Neuron 5:267-281.

Wen R, Song Y, Matthes MT, Yasumura D, Yancopoulos D, LaVail MM, Steinberg RH (1994) Mechanical injury increases bFGF and CNIF expression in the rat retina. Soc Neurosci Abstr 20:1480.

Werner H, Wolschak M, Adamo M, Shen-Orr Z, Roberts CTJ (1989) Developmental regulation of the rat insulin-like growth factor I receptor gene. Proc Natl Acad Sci USA 86:7451-7454. 